\title{
Cognitive-Behavioral Therapy of Obsessive-Compulsive Disorder
}

\author{
Aristides V. Cordioli and Analise Vivan \\ Federal University of Rio Grande do Sul, Porto Alegre \\ Brazil
}

\section{Introduction}

Obsessive-compulsive disorder (OCD) is characterized by the presence of obsessions and/or compulsions that consume time and significantly interfere with the individual's daily routines, work, family or social life, causing marked distress (American Psychiatric Association, 2002). Until the 1980s, OCD was considered a rare disorder. The ECA (Epidemiological Catchment Area) study estimated its prevalence rate between $1.9 \%$ and $3.3 \%$ during individuals' lifetime (Karno et al., 1988). Studies involving children and teenagers demonstrated a prevalence of up to $4.0 \%$ (Fontenelle et al., 2006), with slightly superior rates in boys at a 3:2 ratio, possibly due to the more premature symptoms in males (Rassmussen \& Eisen, 1992; Walitza et a., 2011).

OCD is a chronic neuropsychiatric disorder and the symptoms wax and wane along its course. The possibility of complete remission without treatment is considered to be extremely low (Skoog \& Skoog, 1999). The disorder significantly interferes with individuals' quality of life, with some studies pointing to an impairment level similar to schizophrenia, resulting in incapacitation in the most severe cases of the disorder. OCD was ranked as the tenth cause of years lived in disability worldwide in the Global Burden of Diseases study (Murray \& Lopez, 1996). Until recently it was considered a very difficult-to-treat disorder. This point of view radically changed over the last three decades with the introduction of new and effective methods of treatment: exposure and response prevention (ERP) therapy or cognitive-behavioral therapy (CBT) and anti-obsessive medications. Notwithstanding this progress, OCD is still underdiagnosed in clinical practice, since several patients do not recognize the disorder's symptoms and health professionals do not investigate them regularly during the patient's clinical evaluation.

The symptoms of OCD are usually heterogeneous and it is unclear if it is a single disorder or a group of disorders with common characteristics (such as, for instance, intrusive thoughts and repetitive behaviors). In practice, clinical manifestations, age at symptom's onset, course, neurophysiological, neuropsychological and cognitive aspects, as well as response to treatment, vary greatly from individual to individual. A wide range of comorbidities are usually associated with OCD, the most frequent being major depressive disorder, and other anxiety disorders such as social phobia and specific phobias and tics (Flament et al., 1988; Fontenelle et al., 2006; Ruscio et al., 2010; Torres et al., 2006; Kessler et al., 2005). 


\subsection{Subtypes}

OCD patients have distinct clinical presentations. Factor analytic studies have consistently identified five subgroups of symptoms: (a) contamination obsessions and washing/cleaning compulsions; (b) obsessions about responsibility for causing harm or making mistakes and checking compulsions; (c) obsessions about order and symmetry and ordering/arranging compulsions; (d) repugnant obsessional thoughts concerning sex, religion and violence along with mental compulsive rituals and other covert neutralizing strategies, and (e) hoarding (Abramowitz et al., 2010; Leckman et al.,1997; Mataix-Cols et al., 2005). Some suggest that hoarding should be considered a distinct disorder from OCD, with its own diagnostic criteria in the next edition of the Diagnostic and Statistical Manual of Mental Disorders (DSM-V) (Pertusa et al., 2010; Leckman et al., 2010).

Most patients, however, present a combination of the different dimensions of symptoms, although a specific subtype may predominate. Moreover, it is also common that, throughout an individual's lifetime, the symptoms alternate. For instance, a patient who presents predominance of checking rituals today may, during his/her childhood, have had mainly washing or ordering behaviors.

\subsection{Etiology}

There is strong evidence that neurobiological factors (brain and genetic factors) make certain individuals more susceptible to the development of OCD. The increased prevalence of obsessive-compulsive (OC) symptoms in relatives is well documented, especially among identical twins, which suggests the influence of genetic factors in the disorders etiology (Hettema et al., 2001; Nestadt et al., 2010). Furthermore, the reduction of the symptoms with the use of clomipramine or selective serotonin reuptake inhibitors (SSRIs), the hyperactivity of brain circuits involving the frontal cortex, the thalamus and the striatum, the arising of the obsessive-compulsive symptoms during cerebral diseases like encephalitis or after cranioencephalic traumas or even during the use of certain medications, all point to the involvement of the brain in the physiopathogeny of the disorder.

On the other hand, psychological factors such as faulty learning, distorted beliefs, and catastrophic thoughts are present in most patients, and seem to play an important role in the appearance and maintenance of symptoms.

\section{Theoretical grounds of the cognitive-behavioral therapy}

\subsection{A brief history}

Until the 1960s, the main model for the treatment of OCD was based upon Freud's psychoanalytic theory. The obsessive neurosis, as it was known then, was described as a manifestation of unconscious conflicts related to the anal stage of psychosexual development. The proposed treatment was psychoanalysis or psychoanalytic therapy which, in practice, was ineffective in eliminating the symptoms. The dissatisfaction with such an approach led many authors with a behavioral background to undertake some experiments which were crucial to the present understanding of OCD and the development of new treatment approaches. 


\subsection{The behavioral model}

Mowrer's two-stage or two-factor model (1939) to explain the origins of fear and the avoidance behaviors in anxiety disorders has been adapted in order for one to understand the origins and maintenance of OC symptoms. According to this model, symptoms are originated by classical conditioning: the anxiety associated with the obsessions would be paired to previously neutral objects, places and situations (ex.: public bathrooms, bus seats, numbers, colors), which would then evoke it through conditioning. In a second stage the rituals and the avoidance would be maintained because they reduce or eliminate the anxiety and discomfort, albeit temporarily, reinforcing such behaviors and perpetuating the disorder (operant conditioning - negative reinforcement), and prevent its natural disappearance due to habituation (Salkovskis et al., 1998).

\subsubsection{The habituation phenomenon}

English authors, in the early 1970s, decided to challenge Freud's proposed model, as well as its derived corollaries such as, for instance, that the symptoms, if removed, would be inevitably replaced by others, or that patients could develop a psychotic condition if they were prevented from performing their rituals. They attempted to observe, in volunteers, what could occur if they refrained from performing their rituals or were stimulated to make contact with what they were usually avoiding by reason of their fears.

In a first study, Hodgson and Rachman (1972), while observing patients with cleaning obsessions and washing rituals, found out that they demonstrated rapid and accentuated increase of anxiety when they were asked to touch objects they used to avoid. This anxiety also rapidly decreased when they performed a "satisfactory" washing. In a similar experiment with "checkers" patients, Röper et al. (1973) observed in the same way an immediate increase in anxiety followed by an accentuated decrease after the performance of a checking ritual. Based on these findings, they suggested that there is a functional relation between compulsions and obsessions: compulsions are performed to relieve the anxiety associated to obsessions. This was their function and, at the same time, a tactic learned by the patient to get rid of the anxiety which usually accompanies their obsessions. It is believed that the relief obtained in performing compulsions and with avoidance behaviors is the main factor responsible for the perpetuation of OCD symptoms. The studies also pointed out that the impulse of checking or washing disappeared spontaneously within a 15-180 minute period if patients were requested to refrain from performing the rituals or to remain in contact with the avoided situations or objects. Moreover, at each repetition of the exercises, the intensity of the anxiety and the impulse to perform the rituals decreased. In the case that they repeated the exercises enough times, both the anxiety and the need to perform the rituals disappeared completely. This natural phenomenon became known as habituation and became the basis of ERP therapy. Clinical trials undertaken in the 1970s (Marks et al., 1975; Foa \& Goldstein, 1978) proved the efficacy of ERP therapy in OC symptom reduction, becoming, from then on, one of the first line of treatments for OCD.

\subsubsection{Evidences of efficacy}

ERP therapy is efficient in more than $70 \%$ of the patients who comply with the treatment. A similar or slightly superior efficacy of ERP therapy in relation to SSRIs was found in several 
trials and meta-analyses, definitely consolidating it as the first choice of treatment when rituals predominate and the symptoms are light or moderate in intensity (Foa et al., 2005; Abramowitz, 1997; Rosa-Alcázar et al., 2008).

\subsubsection{Limitations of the model}

Notwithstanding the success attained through ERP therapy in reducing and limiting OC symptoms, some gaps in the behavioral model have become evident. Most patients do not report a relevant history of conditioning which would have originated OC symptoms. The model does not explain why the same individual presents a variety of symptoms of different dimensions and why they modify, waxing and waning over time. It also does not explain why many OCD patients are tormented by aggressive or sexual repugnant thoughts, without having witnessed or committed such acts (Antony et al., 2007).

Despite the promising results ERP also presented limitations: it has little effect over patients who predominantly present pure obsessions not associated to rituals, or obsessive ruminations (doubt, scrupulosity). On the other hand, around 30\% of the patients either abandon the treatment or do not accomplish the homework assignments, especially when the symptoms are severe, or when there is limited insight or overvalued ideas into the contents of the obsessions.

The need to overcome the limitations of the behavioral model and the ERP therapy has led cognitive authors to focus their attention on distorted thoughts and dysfunctional beliefs with catastrophic content present in greater or lower intensity in most individuals afflicted with OCD, highlighting the role of cognition in the origins and maintenance of symptoms (Salkovskis, 1985, 1989, 1999; Rachman, 1997; Salkovskis et al., 1998; Frost \& Steketee, 1999). The hypothesis that such cognitions might be responsible for the elevated degree of anxiety associated with the symptoms was raised, due mainly to the low adherence to treatment and to patients refusing to perform the ERP homeworks, and that its correction through cognitive techniques might improve the treatment efficacy. The addition of cognitive techniques to ERP, which has actually always been seen as complementary to the behavioral techniques, has proven useful, especially in patients with obsessive ruminations and predominance of obsessions of repugnant content, in which it is common to find distorted evaluation about threat, distorted believes about danger, responsibility, need for certainty or the so-called fusion of thought and action, with little insight but with good introspective capacity. This addition resulted in the creation of CBT which has gradually been adopted in OCD treatment.

\subsection{The cognitive-behavioral model}

Today, the cognitive-behavioral model is considered to be the psychological model of OCD with the strongest empirical support (Abramowitz et al., 2009). According to Rachman and de Silva (1978), most people, even those who are not afflicted with OCD, have their minds invaded by improper thoughts of aggressive, obscene or sexual nature, very similar in content to those that torment the OCD patients. However, they do not give any importance to such thoughts and do not attribute any special meaning to their presence; for this reason they easily disappear and do not result in a greater affliction. Still according to the authors, the special catastrophic meaning attributed to the presence of such thoughts ("If I have such 
thoughts, I can perform them" or "If I think about them, it is because I wish to perform them" or "They reveal a secret and perverse side of my character") is responsible for transforming normal intrusive thoughts into obsessions (Rachman \& de Silva, 1978; Rachman, 1997). Rachman's theory, although of great help to the comprehension and treatment of patients tormented by thoughts of repugnant content, does not explain why certain individuals attribute special meaning to such thoughts, while others do not.

Salkovskis et al. (1998) presented an enhanced cognitive model in which they consider the excess of responsibility as a central issue to the origin of obsessions. According to the authors, hypersensitive individuals, due to genetic, neurobiological or environmental factors, present a higher predisposition for catastrophic interpretations. The patient's belief that he/she has the responsibility for preventing future harm to him/herself and especially to others is the crucial ingredient that would lead him/her to perform safety behaviors intended to neutralize such potential risks, such as rituals, avoidance behaviors and checking. The obsessions would persist while the erroneous and distorted beliefs persist, and would decrease when such interpretations weakened. Likewise, the lower the importance attributed by the patients to intrusive thoughts, the lower the impulse to perform the rituals. More recently, Barrera and Norton (2011) investigated a sample of 326 students, and their results corroborate the model previously proposed, concluding that the evaluation of intrusive thoughts is an important predictor of OC symptoms.

A complement of this theory was proposed recently by Rachman (2002) in order to explain the origins of compulsions. Based on Salkovskis's proposition that inflated responsibility would be the central issue of OCD, the author formulated an explanatory hypothesis to the origins of compulsions. They would be repetitive, stereotypical and intentional actions performed by the patient with the intention of preventing future disasters. They would, nonetheless, be some sort of preventive behavior and, in general, associated with indecision and doubt. According to Rachman, checking rituals would be performed when a person who believes to have a big or special responsibility in preventing damage, especially in relation to others, feels insecure that the risk of potential damage may have been effectively reduced or removed, which would lead to repetitive checking as the means of eliminating doubt and possible risk.

\subsubsection{Dysfunctional beliefs in OCD}

Although Salkovskis emphasized the importance of responsibility, several cognitivebehavioral theorists proposed that the following beliefs domains could contribute to the origins and maintenance of OCD symptoms: (1) inflated responsibility, (2) over-importance of thoughts, (3) excessive concern about the importance of controlling one's thoughts, (4) overestimation of threat, (5) intolerance of uncertainty and (6) perfectionism (ObsessiveCompulsive Cognitions Working Group, 1997). Some cognitive authors also suggested and adapted cognitive techniques, originally proposed by A. Beck for the treatment of depression and anxiety disorders to the treatment of OCD symptoms (Salkovskis, 1985, 1999; van Oppen \& Arntz, 1994; Freeston et al., 1996; Salkovskis et al., 1998).

Freeston et al. (1996) found several common characteristics between patients who benefited from cognitive interventions: (1) they greatly value the presence of their obsessions; (2) they believe that their obsessions reflect their true nature (character); (3) they believe that a 
thought, image or impulse is equivalent to putting it into practice; (4) they believe that having a certain thought increases the odds of it actually happening. Nowadays, more and more cognitive techniques have been added to ERP therapy, and the designation of CBT has been gradually adopted.

\subsubsection{Evidence of efficacy of cognitive therapy in OCD}

The efficacy of the isolated use of cognitive therapy in the treatment of OCD has been observed in several clinical trials and in at least one meta-analysis, both in patients with predominant obsessions, considered to be refractory to ERP therapy, and in patients with obsessions and compulsions. The results were considered similar to ERP therapy (Emmelkamp \& Beens, 1991; van Balkom et al., 1994; van Oppen et al., 2005; McLean et al., 2001).

Some of these studies, however, have been criticized: there was less time dedicated to behavioral therapy than to cognitive therapy. There was also the question as to what extent the therapy had indeed been purely cognitive, if this was actually possible, and if the therapists had not, even indirectly, suggested homework assignments, and if it was ethical to request that the patients did not attempt to do expositions or refrain from performing rituals. In practice, the isolated use of cognitive therapy has not been consolidated, giving ground, actually, to CBT.

\subsubsection{Limitations of the model}

Undoubtedly, the cognitive model has allowed a broader comprehension of the obsessivecompulsive phenomena. It has, however, been criticized. Evidence has been inconclusive as to whether the dysfunctional beliefs of OCD patients were specific and distinct from dysfunctional beliefs of patients with other disorders. Tools such as the Obsessive Beliefs Questionnaire (Obsessive-Compulsive Cognitions Working Group, 2005) can hardly distinguish subjects afflicted with OCD from those afflicted by other anxiety disorders. Furthermore, the cognitive model does not explain the reasons why many people perform rituals not preceded by any kind of cognition (obsession). This is very common in individuals who have compulsions to align objects, to do things in a sequenced way or perform certain repetitive behaviors which strongly suggest tics: snapping fingers, looking around, rapping repeatedly, touching, scraping. Likewise, the presence of beliefs in patients with hoarding is very modest and does not seem to play an important role in the origin and maintenance of hoarding symptoms.

Furthermore, until today it has been unclear that the incorporation of cognitive techniques to ERP therapy increases its efficacy, possibly due to heterogeneous samples included in clinical trials, with patients who have different OCD symptom dimensions. There is, however, the clinical impression that, for certain patients and clinical presentations, the use of cognitive techniques may be of great value, as well as for patients who predominantly present obsessions or improper thoughts of sexual, aggressive and blasphemous content and obsessive ruminations, due to their need for certainty. Cognitive techniques may also be helpful for patients with poor insight, or very strict or overvalued dysfunctional beliefs, and who, for these reasons, do not adhere to homework assignments. In such cases, the use of cognitive techniques preceding ERP therapy can reduce the anxiety and improve adherence to ERP exercises. 


\section{Cognitive-behavioral therapy}

The cognitive-behavioral approach to OCD is a structured, brief and focused process. Its goal is to eliminate symptoms through confrontation (exposure) of avoided situations, response prevention (refraining from performing rituals as well as all other neutralization strategies) and to correct faulty appraisals and dysfunctional erroneous beliefs. CBT uses psycho-education, hierarchical symptom list, prescription of behavioral and cognitive home exercises, record sheets and instruments for symptom monitoring, as well as permanent feedback.

When symptoms are mild or moderate and there are no associated comorbidities, CBT is usually brief, lasting for 13-20 sessions, according to the specialists' recommendation (Koran et al., 2007). At the beginning of the therapy, the sessions are weekly and last for approximately 1 hour. As symptoms decrease, the time between sessions can be longer. ERP exercises have as their main objective to develop habituation to stimuli considered to be anxiogenic, while the use of cognitive strategies aims at the correction of automatic thoughts and dysfunctional beliefs, possibly helping adherence and ERP exercises, as well as cognitive restructuring for patients who have a predominance of obsessions (pure obsessionals, repugnant obsessions, strong and persistent doubting).

CBT begins with the patient's assessment, psycho-education, followed by graduated ERP exercises, cognitive exercises, discharge and relapse prevention. Below we describe each one of the stages.

\subsection{Patient assessment}

Patient assessment is undertaken through one or more semi-structured interviews, aimed at establishing the main diagnosis and the presence of comorbidities, as well as collecting data regarding symptom history (age at onset, first symptoms, course of disease), symptoms dimensions, interference in the patient's daily life and family, family members with OC symptoms, presence of medical illnesses, previous treatments (and their effectiveness) and use of medication.

It is important to have in mind that obsessions and compulsions may be present in countless other mental disorders (impulse control disorders, eating disorders, drug addictions, pervasive developmental disorder, etc.); a fact which demands attention in regard to the differential diagnosis. Moreover, comorbidity with some disorders such as impulse control disorders, tics or Tourette, or rheumatic fever may point to different subtypes of OCD, which implies a lower response to CBT and demands complementary therapies.

Still during the assessment stage, some clinical features must be investigated that are usually related to the response to treatment. Studies suggest, although not always agreeing, that the response to EPR may be limited or null in patients who present very severe and incapacitating obsessive-compulsive symptoms; severe anxiety or depression; psychosis; active bipolar disorder; schizotypal personality disorder; histrionic or borderline personality disorder; drugs or alcohol addiction; almost delirious or overvalued beliefs about obsessive ideas; poor insight; lack of motivation towards treatment and non-adherence to home ERP exercises (Neziroglu et al., 1999; Hollander et al., 2002; Raffin et al., 2009). 


\subsection{Starting the therapy}

\subsubsection{Psychoeducation}

Following the confirmation of the diagnosis of $\mathrm{OCD}$, the first step is psychoeducation about OCD, behavioral and cognitive models of OC symptoms and how CBT works. The therapist provides the patient with relevant information, such as types of symptoms (including the definition of obsessions, compulsions, avoidance, neutralization), the etiology of OCD: neurobiological and psychological factors (learning, appraisal and dysfunctional beliefs), course and prognosis, treatment alternatives, etc. It is essential that the patient understand how compulsions, avoidance and other neutralization strategies contribute toward maintaining the disorder to the extent that the reduction of anxiety is a strong reinforcer for these behaviors. They prevent exposure and consequently the natural extinction of anxiety through habituation and disconfirmation of erroneous and catastrophic beliefs.

Psychoeducation can also be applied to the patient's family, when he/she allows it, providing information on the disorder and how they could contribute to the therapy. In a study conducted by van Noppen et al. (1997), patients whose families received some intervention demonstrated superior gains towards those with whom this did not occur, suggesting that family participation in the treatment may be especially useful.

Direct participation of relatives in the rituals, as well as alterations in family daily routine as a result of OCD symptoms, is seen as family accommodation. It is very common for relatives not to know how to behave in the presence of the symptoms displayed by the patient, supporting their rituals, involuntarily reinforcing such behaviors and so interfering in the progress of the treatment. They frequently modify their routines because of the patient's symptoms and demands. The most common behaviors are offering reassurance, answering questions and doubts, waiting for the patient to finish his/her rituals (dressing, bathing) and taking on the responsibilities (Calvocoressi et al., 1995; Storch et al., 2007; Stewart et al., 2008).

\subsubsection{Motivation}

One of the great problems of CBT is non-adherence to ERP exercises due to the increased anxiety, even if transitory, that they provoke. Thus, an important factor to be dealt with is the patient's motivation. It is necessary to assess to what extent he/she is willing to engage in the therapeutic process and tolerate some increase in anxiety levels inherent to ERP exercises. In this stage, the establishment of a healthy therapeutic bond may contribute to the adherence to treatment.

Studies have demonstrated that identifying the stage of change in which the patient is, and if necessary, using motivational interview in the first sessions, has increased the rates of response to CBT, consequently reducing treatment dropout (Rubak et al., 2005; Meyer et al., 2010). Doubts and ambivalence are natural, but it is essential to resolve them before therapy begins. The motivational interview is a method centered on the client and aims at reinforcing motivating change, encouraging patients to identify and solve their ambivalences in relation to the treatment (Miller \& Rose, 2009). Often, in OCD, the lack of motivation and the difficulty in believing in the possibility of changing behavioral patterns (lack of auto-efficacy beliefs) are associated with previous unsuccessful treatments and with overtly intense and crystallized beliefs about obsessions. 


\subsubsection{Elaboration of a hierarchical symptoms list}

If the patient has accepted to undergo CBT, the first task in the therapy is to elaborate a detailed symptoms list, highlighting compulsions and avoidance behavior, which will be very helpful in planning the ERP home exercises. The Y-BOCS Check List may be used to help the elaboration of the symptoms list. The patient is requested to identify, as detailed as possible, the obsessions, compulsions and avoidance perceived throughout the day. It is also important that he/she classify the symptoms by their level of anxiety or discomfort associated with the obsessions or by the level of anxiety or discomfort that he/she supposes to feel when touching objects or facing the situations routinely avoided, or in case he/she refrained from performing rituals when feeling compelled to do so. In order to do that, the patient is requested to attribute a score from 0 to 100 or from 0 to 10 , for the level of anxiety provoked when facing the referred situations. A simplified way of doing this is to use a score from 0 to 4, using the following criteria: symptoms with anxiety level of 1 and 2 (mild); symptoms with anxiety level of 3 (moderate) and symptoms with anxiety level of 4 (severe or very severe). This graduation is helpful in choosing the ERP exercises, since it is recommended to start with those that provoke less anxiety, then move on to the more anxiogenic ones. It is essential to propose exercises that the patient feels capable of accomplishing.

\subsubsection{Assessment measures}

At the beginning of the therapy it is recommended to assess the severity of the symptoms. The scores at baseline serve as reference, and their reduction can be monitored throughout the therapy. The most frequently used scale is the Yale-Brown Obsessive-Compulsive Scale (Y-BOCS) (Goodman et al., 1989), which presents 10 questions; 5 to assess obsessions, and 5 for compulsions, where scores range from 0 (no symptom) to 4 (severe symptoms), with a maximum score of 40 points. The items encompassed are: time, interference, suffering, resistance and the level of control of the symptoms. Another widely known scale is the Obsessive Compulsive Inventory - revised (OCI-R) (Foa et al., 2002), a self-assessment instrument, with 18 questions to evaluate anxiety associated with OC symptoms and severity. It is important that the therapist proceed with the application of the scales in different moments of the therapeutic process, in order to monitor the patient's progress, allowing for occasional adjustments in the therapeutic plan.

\subsubsection{Exercises of exposure and response prevention (ERP)}

The therapy itself begins with the ERP exercises, which are chosen by mutual agreement between the patient and the therapist, to be done in the intervals between the sessions.

Exposure is the direct or imaginary contact with objects, places or situations avoided due to fear, discomfort or disgust they provoke. It causes an increase in anxiety, which can be very high in the first exposures, but decreases in the course of time. The exercises must be done daily and last for at least 15 to 30 minutes or until the anxiety vanishes completely, which can take up to 3 hours, and must be repeated as many times as possible. The longer the exercises and the more frequently they are performed, the better. Examples of exposure exercises for patients who have contamination obsessions: to touch a doorknob, a handrail or money, a wastepaper basket, to sit on a bus seat, to use a public telephone or bathroom. 
Response (or ritual) prevention consists of refraining from performing rituals, or any maneuver intended to reduce or neutralize the anxiety or fear associated with the obsessions. As in exposure, response prevention provokes an initial increase of anxiety, which decreases over time, reducing, therefore, the intensity of the impulse to perform rituals and their frequency. An example of response prevention exercises for patients with contamination obsessions consists in refraining from washing hands after touching money, or from washing their hands when getting home. Other ERP exercises, selected according to the hierarchical symptoms list, consist of refraining from doing any checking, arranging, not attempting to ward off "bad" thoughts, etc. In the case of patients with hoarding, to discard papers, newspapers, magazines, clothes, shoes or other useless or spoiled objects.

The main effect of the exposure as well as of the ritual prevention is the immediate increase of anxiety in the session, which can reach high levels during the first exercises, but decreases until disappearing in an interval usually between 15 to 180 minutes (habituation), and mainly at each repetition of the exercise. The habituation also occurs between sessions. At first, a ritual or an avoidance behavior that the patient has graded as mild intensity (anxiety level of 1 and 2) is chosen from the list of symptoms. In the choice of home exercises it is worth, above all, to consider patient's assessment regarding how much he/she believes to be capable of performing the proposed exercise, making it clear that nothing will be proposed that he/she does not agree with. It is important to make these rules clear because the patients tend to try to get rid of the most severe symptoms, forgetting, many times, to mention the mild ones. Facing mild symptoms at the beginning of the therapy, however, is very important for the therapeutic process. Succeeding in the less anxiogenic exercises helps the patient to feel safe to face the more difficult ones. Furthermore, at the end of the treatment, there may remain residual symptoms, considered to be mild, and the patient may not report or attempt to eliminate them. There is evidence, however, that the persistence of symptoms at the end of the treatment is associated with a higher probability for relapsing (Braga et al., 2010). The objective of the treatment, therefore, must be the complete remission of symptoms, including those that do not interfere much in the individual's daily routines.

Below are some suggestions for the success of ERP exercises:

- Plan the first exercises focusing on compulsions and on avoidance behaviors;

- Start with the easier exercises (symptoms list with anxiety level of 1 and 2) and select those symptoms that the patient believes to have $80 \%$ chances of accomplishing (ERP exercises);

- Choose, together with the patient, 6 to 8 ERP home exercises per week;

- The patient must repeat the exercises as many times as possible: the more often, the better;

- Encourage the patient to do the exercises until the anxiety or discomfort decreases completely or for as long as possible;

- Planned exercises are better than unforeseen ones;

- Make patient aware of the neutralization maneuvers (doing mental or hidden rituals looking fixedly, mental argumentation, praying, counting, repeating dialogues mentally, repeating "the film" or requesting confirmation or reassurance from other people); these maneuvers have the same function as the rituals (reduce or eliminate fears and anxiety) and he/she must refrain from performing them; 
- Together with the patient, identify the trigger situations (situations that activate obsessions and compel him/her to perform rituals throughout the day), and aid him/her in developing confrontation strategies, programming the exercises beforehand.

\subsubsection{Modeling}

In modeling, the therapist uses the learning through observation (social learning), aiming at stimulating the patient to do the ERP exercises. The technique consists of the execution, in front of the patient, of expositions (touching objects) and refraining from performing rituals as a means of motivating him/her to do the same, afterwards inviting him/her to repeat such confrontations. Patients, in general, have an easier time doing the exercises in the presence of other people and, particularly, the therapist. Examples of modeling may include: touching the shoes and then the face, walking barefoot on the office floor, handling objects such as syringes, keys, money, doorknobs, cleaning products, touching the edges of a garbage bin without immediately washing hands.

\subsection{Continuing the treatment}

\subsubsection{Adding cognitive techniques}

The cognitive techniques proposed for OCD must, preferably, be introduced in the therapeutic process when the patient is already able to identify the OC symptoms, avoidance behaviors or anxiety-neutralizing strategies, differentiate obsessions and compulsions from normal thoughts and, mainly, when he/she has already begun the ERP exercises, except in situations in which intrusive repugnant thoughts of a repulsive nature (aggressive, sexually improper, blasphemous), scrupulosity or doubts, predominate, or the patient has poor insight, overvalued ideas and low adherence to ERP exercises. In such cases, when appropriate, the therapy starts with cognitive techniques.

In order for the cognitive strategies to have success, it is necessary that the patient have some introspective capacity, be able to think psychologically, and have curiosity in understanding the symptoms more deeply. The patient must be trained in the identification of automatic catastrophic thoughts and dysfunctional beliefs, the activating situations, as well as their emotional, behavioral and physiological consequences. An interesting exercise is the recording of dysfunctional thoughts, their background and consequences. Next, the patient learns how to classify them according to the beliefs domain to which they belong. For instance, a patient who presents avoidance behavior related to touching doorknobs may have beliefs related to overestimating the risks; a checker, to beliefs about responsibility, and so on. After the identification and association of personal beliefs to the respective domains, the therapist will employ different cognitive techniques aiming at modifying distorted or erroneous appraisals and beliefs.

The cognitive techniques employed in the treatment of OCD are, in general, adaptations of those initially described by Beck for the treatment of depression and by Clark for the treatment of anxiety. Among these techniques, besides the identification and recording of automatic thoughts and dysfunctional beliefs, there are the Socratic questioning, the downward arrow, the examination of the advantages and disadvantages (or of the costbenefit), the pie of responsibility, the examination of the two alternative hypotheses 
(Salkovskis et al., 1998), among others. Its most detailed description may be found in manuals of cognitive therapy and in well-known papers (van Oppen \& Arntz,1994; Salkovskis et al., 1998), but is not within the scope of the present chapter. These are some suggestions, however, that the therapist may employ freely and creatively in the elaboration of strategies that focus mainly on cognitive restructuring.

\subsection{Ending the therapy and relapse prevention}

When the majority of the symptoms have been eliminated, spacing sessions may be proposed and, subsequently, ending the therapy can also be considered. OCD is a chronic disorder and it is important to remember that there is the possibility of relapses, mainly in the patients who did not have complete remission of symptoms (Braga et al., 2005). Thus, the therapist will propose ways of preventing them as the early perception of signs that the symptoms may be coming back, and planning some sessions with the therapist, which are called reinforcement sessions. The reinforcement sessions can be planned and occur at the end of the therapy and through periodic follow-up. They are useful for monitoring the maintenance of the therapeutic gains and contribute to the strengthening of the strategies learned in the therapy.

\section{Group CBT}

Group CBT uses group therapeutic ingredients for influencing treatment results. Several studies have proved the efficacy of group CBT in the treatment of OC as similar to individual ERP therapy or similar to sertraline (Fals-Stewart et al., 1993; Cordioli et al., 2003; Sousa et al., 2006; Jonsson et al., 2009; Jonsson et al, 2011). Follow-up studies have proven that its effects are maintained in the long run, after discharge (Braga et al., 2010; Borges et al., 2011). Group CBT presents a more favorable cost/benefit relation; with costs five times lower than individual therapy, besides making the treatment available to a larger number of people. It is an interesting approach to use in institutions with high treatment demand. Besides, it is supposed that the group focus may improve the adherence to treatment, an important limitation of CBT for OCD.

\section{Use of medication}

Both psychotherapy and medications present limitations and, occasionally, contraindications. Several studies do not demonstrate additional advantages in the association of medication and therapy. The results of recent studies, however, reinforce the recommendation of the Consensus of Experts for the Treatment of Obsessive-Compulsive Disorder, which suggests the association whenever possible (March et al., 1997). It is interesting, for instance, the observation that CBT seems to be effective even in patients who do not respond or who respond partially to treatments with anti-obsessive medications (Simpson et al., 1999; Tolin et al., 2004; Tenneij et al., 2005).

In some cases, however, one of the two modalities of treatment may be preferred, at least in the beginning of the treatment. The CBT may be the preferred choice for patients who present a predominance of compulsions and avoidance behavior, whose OC symptoms are mild or moderate, who do not tolerate the side effects of the medication or do not accept using them, and who do not present comorbidities which demand the addition of 
medication. It is also the treatment of choice of pregnant women, or other patients to whom there may be some contraindication in the use of anti-obsessives, as in bipolar disorder. Medications are the treatment of choice when OC symptoms are severe or incapacitating, when severe depressive or anxiety symptoms are present, when there are almost delusional convictions towards the contents of the obsessions, associated comorbidities which demand pharmacological treatment, or the patient refuses or does not adhere to CBT exercises.

\section{Conclusion}

The behavioral and cognitive models of OCD allow for a better comprehension of the OC symptoms. They also allow for the proposition of a variety of techniques and strategies effective in reducing OC symptoms in most patients and even the possibility of completely eliminating them. These results completely changed the pessimistic perspectives that until recently predominated toward psychotherapeutic treatment of OCD. Much advancement, however, can be made in the development of new strategies that may reach those patients who have not yet benefited from existing treatment. The definition of more homogeneous subgroups, it is believed, may result in more specific treatments, both from a psychotherapeutic and a pharmacological point of view.

Moreover, when it comes to public health, the explanation to the population of the manifestations of the OCD and its early treatment, especially in children and teenagers afflicted with the disorder, as well as a greater availability of the CBT as a public service, are future challenges.

\section{References}

Abramowitz, J. (1997). Effectiveness of psychological and pharmacological treatments for obsessive-compulsive disorder: A quantitative review of the controlled treatment literature. Journal of Consulting and Clinical Psychology, Vol.65, No.1, (February 1997), pp. 44-52, ISSN 0022-006X

Abramowitz, J., Taylor, S., \& McKay, D. (2009). Obsessive-compulsive disorder. Lancet, Vol.374, No.9688, (August 2009), pp. 491-499, ISSN 0140-6736

Abramowitz, J., Deacon, B., Olatunji, B., Wheaton, M., Berman, N., Losardo, D., Timpano, K., McGrath, P., Riemann, B., Adams, T., Björgvinsson, T., Storch, E., \& Hale, L. (2010). Assessment of obsessive-compulsive symptom dimensions: Development and evaluation of the Dimensional Obsessive-Compulsive Scale. Psychological Assessment, Vol.22, No.1, (March 2010), pp. 180-198, ISSN 1040-3590

American Psychiatric Association. (2002). DSM-IV-TR - Manual diagnóstico e estatístico de transtornos mentais (4ed). Artmed, ISBN 9788573079852 , Porto Alegre, Brazil

Antony, M., Purdon, C., \& Summerfeldt, L. (2007). Psychological treatment of obsessivecompulsive disorder: Fundamentals and Beyond. American Psychological Association, ISBN 1591474841, Washington D.C., USA

Barrera, T., \& Norton, P. (2011). The appraisal of intrusive thoughts in relation to obsessional-compulsive symptoms. Cognitive Behaviour Therapy, Vol.1, No.1, (April 2011), ISSN 1651-2316 
Borges, C., Meyer, E., Ferrão, Y., Souza, F., \& Cordioli, A.V. (2011). Cognitive-behavioral group therapy versus sertraline for obsessive-compulsive disorder: five-year follow-up. Psychotherapy and Psychosomatics, Vol.80, (May 2011), pp. 249-250, ISSN 1423-0348

Braga, D., Cordioli, A., Niederauer, K., \& Manfro, G. (2005). Cognitive-behavioral group therapy for obsessive-compulsive disorder: a 1-year follow-up. Acta Psychiatrica Scandinavica, Vol.112, No.3, (September, 2005), pp.180-186, ISSN 0001-690X

Braga, D., Manfro, G., Niederauer, K., \& Cordioli, A. (2010). Full remission and relapse of obsessive-compulsive symptoms after cognitive-behavioral group therapy: a twoyear follow-up. Revista Brasileira de Psiquiatria, Vol.32, No.2, (June 2010), pp. 164168, ISSN 1516-4446

Calvocoressi, L., Lewis, B., Hariis, M., Trufan, S., Goodman, W., McDougle, C., \& Price, L. (1995). Family accommodation in obsessive-compulsive disorder. The American Journal of Psychiatry, Vol.152, No.3, (March 1995), pp.441-443, ISSN 0002-953X

Cordioli, A.V., Heldt, E., Bochi, D., Margis, R., Sousa, M., Tonello, J., Manfro, G., Kapczinski, F. (2003).Cognitive-behavioral group therapy in obsessive-compulsive disorder: a randomized clinical trial. Psychotherapy and Psychosomatics, Vol.72, No.4, pp.211216, ISSN 0033-3190

Emmelkamp, P., \& Beens, H. (1991). Cognitive therapy with obsessive-compulsive disorder: a comparative evaluation. Behaviour Research and Therapy, Vol.29, No.3, pp.293-300, ISSN 0005-7967

Fals-Stewart, W., Marks, A., \& Schafer, J. (1993). A comparison of behavioral group therapy and individual behavior therapy in treating obsessive-compulsive disorder. Journal of Nervous and Mental Disease, Vol.181, No.3, (March 1993), pp. 189-193, ISSN 00223018

Flament, M., Whitaker, A., Rapoport, J., Davies, M., Berg, C., Kalikow, K., Sceery, W., \& Shaffer, D. (1988) Obsessive compulsive disorder in adolescence: An epidemiological study. Journal of the American Academy of Child $\mathcal{E}$ Adolescence Psychiatry, Vol.27, No.6, (November 1988), pp. 764-771, ISSN 0890-8567

Foa, E., \& Goldstein, A. (1978). Continuos exposure and complete response prevention in the treatment of obsessive-compulsive neurosis. Behavioral Therapy, Vol.9, No.5, (November 1978), pp. 821-829

Foa, E., Huppert, J., Leiberg, S., Langner, R, Kichic, R., Hajcak, G., \& Salkovskis, P. (2002). The Obsessive Compulsive Inventory: Development and validation of a short version. The Psychological Assessment, Vol.14, No.4, (December 2002), pp. 485-495, ISSN 1040-3590

Foa, E., Liebowitz, M., Kozak, M., Davies, S., Campeas, R., Franklin, M., Huppert, J., Kjernisted, K., Rowan, V., Schmidt, A., Simpson, H., \& Tu, X. (2005). Randomized, placebo-controlled trial of exposure and ritual prevention, clomipramine, and their combination in the treatment of obsessive-compulsive disorder. The American Journal of Psychiatry, Vol.162, No.1, (January 2005), pp. 151-161, ISNN 0002-953X

Fontenelle, L., Mendlowicz, M., \& Versiani, M. (2006). The descriptive epidemiology of obsessive-compulsive disorder. Progress in Neuropsychopharmacology and Biological Psychiatry, Vol.30, No.3, (May 2006), pp. 327-337, ISSN 0278-5846 
Freeston, M., Rhéaume, J., \& Ladouceur, R. (1996). Correcting faulty appraisal of obsessional thoughts. Behavior Research and Therapy, Vol.34, No.5-6, (May-June 1996), pp. 433446, ISSN 0005-7967

Frost, R., \& Steketee, G. (1999) Issues in the treatment of compulsive hoarding. Cognitive and Behavioral Practice, Vol.6, No. 4, pp. 397-407

Goodman, W., Price, L., Rasmussen, S. (1989). The Yale-Brown obsessive-compulsive scale (YBOCS) part I: development, use, and reliability. Archives of General Psychiatry, Vol.46, No.11, (November 1989), pp. 1006-1011, ISSN 0003-990X

Hettema, J., Neale, M., \& Kendler, K. (2001). A review and meta-analysis of the genetic epidemiology of anxiety disorders. The American Journal of Psychiatry, Vol.158, No.10, (October 10), pp. 1568-78, ISSN 0002-953X

Hodgson, R., \& Rachman, S. (1972). The effects of contamination and washing in obsessional patients. Behaviour Research and Therapy, Vol.10, No.02, (May 1972), pp. 111-117, ISSN 0005-7967

Hollander, E., Bienstock, C., Koran, L., Pallanti, S., Marazziti, D., Rasmussen, S., Ravizza, L., Benkelfat, C., Saxena, S., Greenberg, B., Sasson, Y., \& Zohar, J. (2002). Refractory obsessive-compulsive disorder: state of the art treatment. Journal of Clinical Psychiatry, Vol.63, pp. 20-29, ISSN 0160-6689

Jonsson, H., \& Hougaard, E. (2009). Group cognitive behavioural therapy for obsessivecompulsive disorder: a systematic review and meta-analysis. Acta Psychiatrica Scandinavica, Vol.119, No.2, (February 2009), pp. 98-106, ISSN 1600-0447

Jonsson, H., Hougaard, E., \& Bennedsen, B. (2011). Randomized comparative study of group versus individual cognitive behavioural therapy for obsessive compulsive disorder. Acta Psychiatrica Scandinavica, Vol.123, No.5, (May 2011), pp. 387-397, ISSN 16000447

Karno, M., Golding, J., Sorenson, S., \& Burnam, M. (1988). The epidemiology of obsessivecompulsive disorder in five US communities. Archives of General Psychiatry, Vol.45, No. 2, (December 1988), pp. 1094-1099, ISSN 0003-990X

Kessler, R., Berglund, P., Demler, O., Jin, R., \& Walters, E. (2005). Lifetime prevalence and age-of-onset distributions of DSM-IV disorders in the National Comorbidity Survey Replication. Archives of General Psychiatry, Vol.62,No.6, (June 2005), pp. 593-602, ISSN 0003-990X

Koran, L., Hanna, G., Hollander, E., \& Nestadt, G. (2007). Practice guideline for the treatment of patients with obsessive-compulsive disorder. The American Journal of Psychiatry, Vol.164, No.7, (July 2007), pp. 5-53, ISSN 0002-953X

Leckman, J., Grice, D., \& Boardman, J., Zhang, H., Vitale, A., Bondi, C., Alsobrook. J., Peterson, B., Cohen, D., Rasmussen, S., Goodman, C., McDougle, C., \& Pauls, D. (1997). Symptoms of obsessive-compulsive disorder. The American Journal of Psychiatry, Vol.154, No.7, (July 1997), pp. 911-917, ISSN 0002-953X

Leckman, J., Denys, D., Simpson, B., Mataix-Cols, D., Hollander, E., Saxena, S., Miguel, E., Rauch, S., Goodman, W., Phillips, K., \& Stein, D. (2010). Obsessive-compulsive disorder: a review of the diagnostic criteria and possible subtypes and dimensional specifiers for DSM-V. Depression and Anxiety, Vol.27, No.6, (June 2010), pp. 507-527, ISSN 1520-6394 
March, J., Frances, A., Kahn, D., \& Carpenter, D. (1997). The expert consensus guideline series: treatment of obsessive-compulsive disorder. Journal of Clinical Psychiatry, Vol.58, No.4, pp. 1-72, ISSN 0160-6689

Marks, I., Hodgson, R., \& Rachman, S. (1975). Treatment of chronic obsessive-compulsive neurosis by in-vivo exposure - a two year follow-up and issues in treatment. The British Journal of Psychiatry, Vol.127, (October 1975), pp. 349-364, ISSN 0007-1250

Mataix-Cols, D., Rosário-Campos, M., Leckman, J. (2005). A multidimensional model of obsessive-compulsive disorder. The American Journal of Psychiatry, Vol.162, No.2, (February 2005), pp. 228-238, ISSN 0002-953X

McLean, P., Whittal, M., Thordarson, D., Taylor, S., Söchting, I., Koch, W., Paterson, R., \& Anderson, K. (2001). Cognitive versus behavior therapy in the group treatment of obsessive-compulsive disorder. Journal of Consulting and Clinical Psychology, Vol.69, No.2, (April 2001), pp. 205-214, ISSN 0022-006X

Meyer, E., Souza, F., Hekdt, E., Knapp, P., Cordioli, A., Shavitt, R., \& Leukefeld, C. (2010). A randomized clinical trial to examine enhancing cognitive-behavioral group therapy for obsessive-compulsive disorder with motivational interviewing and thought mapping. Behavioural and Cognitive Psychotherapy, Vol.38, No.3., (May 2010), pp. 319-336, ISSN 1469-1833

Miller, W., \& Rose, G. (2009). Toward a theory of motivational interviewing. The American Psychologist, Vol.64, No.6, (September 2009), pp. 527-537, ISSN 1935-990X

Mowrer, O. (1939). A stimulus-response analysis of anxiety and its role as a reinforcing agent. Psychological Review, Vol.46, pp. 553-565

Murray, C., \& Lopez, A. (1996). The global burden of disease. Harvard University Press, ISBN 9780674354487, Cambridge, USA

Nestadt, G., Grados, M., \& Samuels, J. (2010). Genetics of obsessive-compulsive disorder. Psychiatric Clinics of North America, Vol.33, No.1, (March 2010), pp.141-158 ISSN 1558-3147

Neziroglu, F., Stevens, K., Yaryura-Tobias, J. (1999). Overvalued ideas and their impacto $n$ treatment outcome. Revista Brasileira de Psiquiatria, Vol.21, No.4, (December 1999), pp. 209-216, ISSN 1516-4446

Obsessive-Compulsive Cognitions Working Group. (1997). Cognitive assessment of obsessive-compulsive disorder. Behaviour Research and Therapy, Vol.35, No.7, (July 1997), pp. 667-681, ISSN 0005-7967

Obsessive-Compulsive Cognitions Working Group. (2005). Psychometric validation of the Obsessive Belief Questionnaire and the interpretation of intrusions inventory: part 2. Factor analyses and testing of a brief version. Behaviour Research and Therapy, Vol.43, No.11, (November 2005), pp. 1527-1542, ISSN 0005-7967

Pertusa, A., Frost, R., Fullana, M., Samuels, J., Steketee, G., Tolin, D., Saxena, S., Leckman, J., \& Matix-Cols, D. (2010). Refining the diagnostic boundaries of compulsive hoarding: a critical review. Clinical Psychology Review, Vol.30, No.4, (June 2010), pp. 371-386, ISSN 1873-7811

Rachman, D., \& de Silva, P. (1978). Abnormal and normal obsession. Behaviour Research and Therapy, Vol.16, No.4, pp. 233-248, ISSN 0005-7967

Rachman, S. (1997). A cognitive theory of obsessions. Behaviour Research and Therapy, Vol.35, No.9, (September 1997), pp. 793-780, ISSN 0005-7967 
Rachman, S. (2002). A cognitive theory of compulsive checking. Behaviour Research and Therapy, Vol.40, No.6, (June 2002), pp. 625-639, ISSN 0005-7967

Raffin, A., Fachel, J., Ferrão, Y., de Souza, F., \& Cordioli, A. (2009). Predictors of response to group cognitive-behavioral therapy in the treatment of obsessive-compulsive disorder. European Psychiatry, Vol.24, No.5, (June 2009), pp. 297-306, ISSN 0924-9338

Rassmussen, A., \& Eisen, J. (1992). The epidemiological and clinical features of obsessivecompulsive disorder. Psychiatric Clinics of North America, Vol.15, No.4, (December 1992), pp. 743-758, ISSN 0193-953X

Röper, G., Rachman, S., \& Hodgson, R. (1973). An experiment on obsessional checking. Behaviour Research and Therapy, Vol.11, No.3, (Augusti 1973), pp. 271-277, ISSN 0005-7967

Rosa-Alcázar, A., Sanchez-Meca, J., Gomez-Conesa, A., \& Marin-Martinez, F. (2008). Psychological treatment of obsessive-compulsive disorder: a meta-analysis. Clinical Psychology Review, Vol.28, No.8, (December 2008), pp. 1310-1325, ISSN 1873-7811

Rubak, S., Sandbaek, A., Lauritzen, T., \& Christensen, B. (2005). Motivational interviewing: a systematic review and meta-analysis. British Journal of General Practice, Vol.55, No. 513, (April 2005), pp. 305-312, ISSN 0960-1643

Ruscio, A., Stein, D., Chiu, W., \& Kessler, R. (2010). The epidemiology of obsessivecompulsive disorder in the National Comorbidity Survey Replication. Molecular Psychiatry, Vol.15, No.1, (January 2010), pp. 53-63, ISSN 1476-5578

Salkovskis, P. (1985). Obsessional-compulsive problems: a cognitive-behavioral analysis. Behavior Research and Therapy, Vol.23, No.5, pp. 571-583, ISSN 0005-7967

Salkovskis, P. (1989). Cognitive-behavioural factors and the persistence of intrusive thoughts in obsessional problems. Behavior Research and Therapy, Vol.27, No.6, pp.677-682, ISSN 0005-7967

Salkovskis, P., Forrester, E., \& Richards, C. (1998). Cognitive-behavioural approach to understanding obsessional thinking. The British Journal of Psychiatry, Vol.173, No.35, pp. 53-63, ISSN 0960-5371

Salkovskis, P. (1999). Understanding and treating obsessive-compulsive disorder. Behavior Research and Therapy, Vol.37, No.1, (July 1999), pp. 29-52, ISSN 0005-7967

Simpson, H., Gorfinkle, K., Liebowitz, M. (1999). Cognitive-behavioral therapy as an adjunct to serotonin reuptake inhibitors in obsessive-compulsive disorder: an open trial. Journal of Clinical Psychiatry, Vol.60, No.9, (September 1999), pp. 584-590, ISSN 01606689

Skoog, G., \& Skoog, I. (1999). A 40-year follow-up of patients with obsessive-compulsive disorder. Archives of General Psychiatry, Vol.56. No.2, (February 1999), pp. 121-127, ISSN 0003-990X

Sousa, M., Isolan, L., Oliveira, R., Manfro, G., \& Cordioli, A. (2006). A randomized clinical trial of cognitive-behavioral group therapy and sertraline in the treatment of obsessive-compulsive disorder. Journal of Clinical Psychiatry, Vol.67, No.7, (July 2006), pp. 1133-1139, ISSN 0160-6689

Stewart, S., Beresin, C., Haddad, S., Egan Stack, D., Fama, J., Jenike, M. (2008) Predictors of family accommodation in obsessive-compulsive disorder. Annals of Clinical Psychiatry, Vol.20, No.2, (April-June 2008), pp. 65-70, ISSN 1547-3325 
Storch, E., Geffken, G., Merlo, L., Jacob, M., Murphy, T., Goodman, W., Larson, M., Fernandez, M., \& Grabill, K. (2007). Family accommodation in pediatric obsessivecompulsive disorder. Journal of Clinical Child and Adolescent Psychology, Vol.36, No.2, (April-June 2007), pp. 207-216, ISSN 1537-4416

Tenneij, N., van Megen, H, Denys, D., Westenberg, H. (2005). Behavior therapy augments response of patients with obsessive-compulsive disorder responding to drug treatment. Journal of Clinical Psychiatry, Vol.66, No.9, (September 2005), pp. 11691175, ISSN 0160-6689

Tolin, D. Maltby, N., Diefenbach, G., Hannan, S., Worhunsky, P. (2004). Cognitivebehavioral therapy for medication nonresponders with obsessive-compulsive disorder: a wait-list-controlles open trial. Journal of Clinical Psychiatry, Vol.65, No.7, (July 2004), pp. 922-931, ISSN 0160-6689

van Balkom A., van Oppen, P., Vermeulen, A., van Dyck, R., Nauta, M., \& Vorst, H. (1994). A meta-analysis on the treatment of obsessive-compulsive disorder: a comparasion of antidepressants, behavior, and cognitive therapy. Clinical Psychology Review, Vol.14, No.5, pp. 359-3981

van Noppen B., Steketee, G., McCorkle, B. \& Pato, M. (1997). Group and multifamily behavioral treatment for obsessive compulsive disorder: a pilot study. Journal of Anxiety Disorders, Vol.11, No.4, (July-August 1997), pp. 431-446, ISSN 0887-6185

van Oppen, P., \& Arntz, A. (1994). Cognitive therapy for obsessive-compulsive disorder. Behavior Research and Therapy, Vol.32, No.1, (January 1994), pp. 79-87, ISSN 00057967

van Oppen, P., van Balkom, A., de Haan, E., \& van Dyck, R. (2005). Cognitive therapy and exposure in vivo alone and in combination with fluvoxamine in obsessivecompulsive disorder: a 5-year follow-up. Journal of Clinical Psychiatry, Vol.66, No.11, (November 2005), pp. 1415-1422, ISSN 0160-6689

Walitza, S., Melfsen, S., Jans, T., Zellmann, H., Wewetzer, C., \& Warke, A. (2011). Obsessivecompulsive disorder in children and adolescents. Deutsches Aerzteblatt International, Vol.108, No.11, (March 2011), pp. 173-179, ISSN 1866-0452 


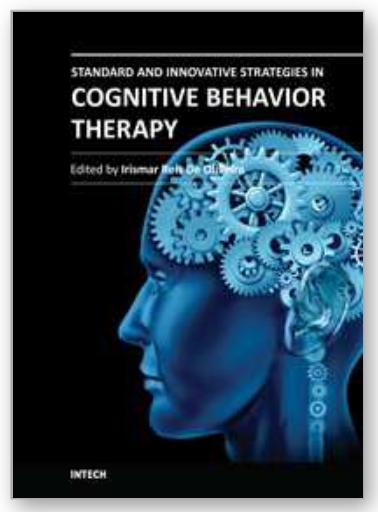

\author{
Standard and Innovative Strategies in Cognitive Behavior Therapy \\ Edited by Dr. Irismar Reis De Oliveira
}

ISBN 978-953-51-0312-7

Hard cover, 190 pages

Publisher InTech

Published online 14, March, 2012

Published in print edition March, 2012

Cognitive-behavioral therapy (CBT) is the fastest growing and the best empirically validated psychotherapeutic approach. Written by international experts, this book intends to bring CBT to as many mental health professionals as possible. Section 1 introduces basic and conceptual aspects. The reader is informed on how to assess and restructure cognitions, focusing on automatic thoughts and underlying assumptions as well as the main techniques developed to modify core beliefs. Section 2 of this book covers the cognitive therapy of some important psychiatric disorders, providing reviews of the recent developments of CBT for depression, bipolar disorder and obsessive-compulsive disorder. It also provides the latest advances in the CBT for somatoform disorders as well as a new learning model of body dysmorphic disorder. Two chapters on addiction close this book, providing a thorough review of the recent phenomenon of Internet addiction and its treatment, concluding with the CBT for substance abuse.

\title{
How to reference
}

In order to correctly reference this scholarly work, feel free to copy and paste the following:

Aristides V. Cordioli and Analise Vivan (2012). Cognitive-Behavioral Therapy of Obsessive-Compulsive Disorder, Standard and Innovative Strategies in Cognitive Behavior Therapy, Dr. Irismar Reis De Oliveira (Ed.), ISBN: 978-953-51-0312-7, InTech, Available from: http://www.intechopen.com/books/standard-and-innovativestrategies-in-cognitive-behavior-therapy/cognitive-behavioral-therapy-of-obsessive-compulsive-disorder

\section{INTECH}

open science | open minds

\section{InTech Europe}

University Campus STeP Ri

Slavka Krautzeka 83/A

51000 Rijeka, Croatia

Phone: +385 (51) 770447

Fax: +385 (51) 686166

www.intechopen.com

\section{InTech China}

Unit 405, Office Block, Hotel Equatorial Shanghai

No.65, Yan An Road (West), Shanghai, 200040, China

中国上海市延安西路65号上海国际贵都大饭店办公楼 405 单元

Phone: +86-21-62489820

Fax: $+86-21-62489821$ 
(C) 2012 The Author(s). Licensee IntechOpen. This is an open access article distributed under the terms of the Creative Commons Attribution 3.0 License, which permits unrestricted use, distribution, and reproduction in any medium, provided the original work is properly cited. 